\title{
Effects of progressive inquiry on cognitive and affective learning outcomes in adolescents' geography education
}

\author{
Merja Kuismaa ${ }^{\text {, Petri Nokelainen }}{ }^{\mathrm{a}, \mathrm{b}}$ \\ ${ }^{a}$ University of Tampere, Finland \\ ${ }^{b}$ Tampere University of Technology, Finland
}

Article received 19 June 2017 / Revised 5 November 2017 / Accepted 16 July 2018 / available online 27 July

\begin{abstract}
Adolescents need skills to acquire information and compare, analyze, transform, and experiment with knowledge. However, little research has been conducted on the content and pedagogical practices that are necessary to achieve these skills. This article seeks to contribute to this discussion because geography enables the attainment of the socalled higher-order thinking skills, and the progressive inquiry model provides suitable pedagogical practices. This study provides empirical evidence on the effects of the progressive inquiry teaching method and learning model on cognitive and affective learning outcomes. This paper focuses on learning outcomes among 253 Finnish middle and upper secondary school students. This comparison between different developmental stages reveals the effects of the teaching and learning method in question. The results indicate that the progressive inquiry method improves cognitive learning results at both educational levels in the context of geography education. The research provides evidence that older students benefit more from the learning model. Additionally, the self-regulated learning skills that the students possess at the beginning of the course do not affect their cognitive learning outcomes. Progressive inquiry clearly enhances the motivation levels of middle school students; however, the effect on the motivation level was more ambiguous among the upper secondary students.
\end{abstract}

Keywords: active learning; computer-supported collaborative learning; inquiry learning; learning outcomes; progressive inquiry 


\section{Introduction}

Inquiry-based learning, such as the progressive inquiry method, requires a great deal of effort from students and teachers, especially when information and communication technology (ICT) is used as a learning tool (Cerratto-Pargman, Järvelä, \& Milrad, 2012; Winne, 1995). Nevertheless, the benefits of inquiry-based learning surpass its drawbacks. One of these benefits is the enhancement of essential citizenship skills in the $21^{\text {st }}$ century societies (Banchi \& Bell, 2008; Hakkarainen, Palonen, Paavola, \& Lehtinen, 2004). Although the novelty of many of these skills is controversial, certain skills are commonly seen as necessary for coping with and succeeding in a knowledge- and information-based society (Pauw, 2015). Learners in $21^{\text {st }}$ century societies need skills to acquire information, as well as inquire, analyze, transform, construct, compare, and experiment with knowledge (e.g., Cerratto-Pargman et al., 2012). Despite studies that scrutinize the definitions of these skills, little research has focused on the content that should be used to teach these skills (Pauw, 2015). This article seeks to contribute to this discussion by introducing geography as a context for higher-order thinking and progressive inquiry as a pedagogical model. Research was conducted using a carefully planned quasiexperimental design that compared intervention and control groups, and investigated intact groups to reduce the reactive effects of the experimental procedure, thus increasing external validity (see Dimitrov \& Rumrill, 2003). Since the first author of this paper was in a position to act immediately when data was missing (e.g., a survey response), the data was completed right away by asking the student to fill in the missing form. The research design was made in such a way that it enabled the researchers to investigate two different developmental stages of learners in order to find differences in learners' self-regulated learning skills, especially related to motivation, and their effects on learning outcomes. Since self-regulated learning processes are developmental by nature (Loyens, Magda, \& Rikers, 2008), we compared two data sets: one from middle school and one from upper secondary school.

According to Wolters, Pintrich and Karabenic (2003, p. 5), "self-regulated learning is an active, constructive process whereby learners set goals for their learning and then attempt to monitor, regulate, and control their cognition, motivation, and behavior, guided and constrained by their goals and the contextual features in the environment." Based on an analysis of major research trends (Wolters \& Taylor, 2012), it encompasses four phases (forethought/planning, monitoring, control/management, reaction/reflection) and four related areas of self-regulation (cognition, motivation, behavior, context) for each phase. In the current study, our focus is on the motivational aspects of self-regulated learning in control (or management) phase (Pintrich, 2004; Wolters, Pintrich, \& Karabenic, 2003; Wolters \& Taylor, 2012; Zimmerman, 2000; Zimmerman \& Schunk, 2008).

One of the key features of geography as a school subject is that it provides content that can mediate the attainment of higher-order thinking skills, such as analyzing, synthesizing, and problem solving (Leat, 1997; Nagel, 2008; Pauw, 2015). Therefore, geography differs from other school subjects due to its analytic and synthetic nature. Learners are challenged with questions about who, why, where, when and how this happen, as well as finding causal relationships within and between phenomena of human and physical geography (Leat, 1997; 1998). As geography provides excellent possibilities for improving learners' $21^{\text {st }}$ century skills, courses of geography were chosen for this study. The following sections present the theories that underlie the research design of this study, followed by a description of the methods.

\subsection{Geographical thinking skills}

Geography plays a central role in school curricula that educates adolescents for the future (Pauw, 2015). Geography deals with complex issues, such as globalization and global warming, which are included 
in the geography curricula of middle schools and upper secondary schools (Finnish National Board of Education, 2015; Pauw, 2015). Moreover, thinking geographically is a skill that helps adolescents understand where something is, how the location affects its characters, and its relations to other phenomena (Nagel, 2008). Adolescents need knowledge about different cultures in order to understand global and local issues. In our study, pre-tests and post-tests were designed according to Bloom's taxonomy to determine students' abilities to recollect factual knowledge, analyze information, and thinking synthetically (Bloom, Hastings, \& Madaus, 1981). Moreover, multiple choice questions were designed to measure students' abilities to recollect factual knowledge, and open-ended questions were created to measure their understanding and abilities to apply, analyze, synthesize, and assess knowledge.

In order to succeed in their future careers and personal lives, adolescents require innovative and creative thinking skills, problem solving skills, and communication and collaboration skills that can be taught via geographic studies (Leat, 1997; Nagel, 2008). These skills were implemented into the design of the geography courses of this study. According Nagel (2008, p. 354), "Geography provides students an inexhaustible context for creativity in an interdependent world." Additionally, geography can teach metacognitive skills, thus making the learning processes visible to the learner, which can be transferred to other subject domains (Leat, 1997; 1998).

In this study, middle and upper secondary school students studied human and physical geography. The middle school students studied the geographical phenomena in the European context, while the upper secondary school students studied these phenomena from a global perspective. Both age groups were expected to execute geographical thinking, and analyze and synthesize different phenomena collaboratively through a type of inquiry-based learning called progressive inquiry.

\subsection{Progressive inquiry as a teaching and learning model}

Progressive inquiry is a teaching and learning model that falls under the umbrella of the active learning approach where students construct knowledge themselves (Prince \& Felder, 2006). Active learning activities involve learner-centered teaching strategies that seek to activate students, while progressive inquiry introduces students to a new way of creating knowledge that resembles the scientific inquiry process (Paavola \& Hakkarainen, 2005). This is a cyclic process of creating a context for learning, determining the research questions, constructing working theories, seeking and deepening knowledge, conducting a critical assessment of knowledge advancement, and sharing expertise (Muukkonen, Hakkarainen, \& Lakkala, 1999). The theoretical framework of progressive inquiry consists of the following theories and models: (1) the knowledgebuilding theory of intentional learning and expertise (Bereiter, 2002; Scardamalia, 2002; Scardamalia \& Bereiter, 1994); (2) the interrogative model of inquiry (Hintikka, 1982, 1985), (3) the theory of expansive learning (Engeström, 1999), and (4) the model of knowledge-creating companies (Nonaka \& Takeuchi, 1995).

The knowledge-building processes involved in the progressive inquiry model include monologic ("knowledge acquisition"), dialogic ("participation") and trialogic ("knowledge creation") levels of learning (Paavola \& Hakkarainen, 2005). Knowledge acquisition represents a subjective or mental view of human learning, participation represents an inter-subjective or social view of learning, and knowledge creation represents an interaction between individuals, communities, and shared knowledge-laden artifacts being developed (Hakkarainen, 2009). The progressive inquiry approach underlines the key role of the active learner and collaboration when directing one's behavior. It also presupposes that inquiry is a question-driven process of understanding what is needed for knowledge creation, that mediating artifacts can induce learning, and that learning is an expansive process where activities produce new activities.

Progressive inquiry provides learners with a high level of autonomy. To be successful in such a learning process, the learner requires various forms of support from the teacher, as well as self-regulated learning skills (Winne, 1995). According to Zimmerman (1998), the learner's behavior should be intrinsic rather than extrinsic (e.g., regulated by the teacher, parents, or peers) because it enables self-regulated learning to take place. Self-regulated learning skills become fortified as the learner gains experience with controlling 
his or her cognition, motivation, behavior (especially effort regulation), physical learning environment, and study schedule (Winne, 1995; Wolters, Pintrich, \& Karabenick, 2003). Self-regulatory skills are not fixed individual characteristics as they involve contextual, developmental, and individual constraints (Pintrich, 1999; Wolters, Pintrich, \& Karabenick, 2003). When participating in collaborative learning, regulative processes can become even more complex through the interaction between self-regulative, co-regulative, and socially shared regulation processes (Järvelä \& Hadwin, 2013).

From the competence research perspective, all these three levels of learning contribute to the holistic development of the individual (cognitive, metacognitive) and subject-related (conceptual, functional) competences (Le Deist \& Winterton, 2005). Self-regulation relates to metacognitive ("learning to learn") competence development (Nokelainen, Kaisvuo, \& Pylväs, 2016) and is, therefore, a prerequisite of inquirybased pedagogy because it is needed at the monologic level of knowledge-building processes in technologymediated learning. Co-regulation relates to the dialogic level and socially shared regulation is needed at the trialogic level. This study focuses on the motivational aspects of regulation. Self-regulated learning processes are developmental by nature (Loyens, Magda, \& Rikers, 2008); therefore, we aim to compare the effects of progressive inquiry on the learning outcomes of two different age groups of adolescents.

The progressive inquiry teaching and learning method — with its collaborative way of working — suits the pedagogical framework of geography education because geographical thinking involves question-making, multiple resources to seek answers, analytic and synthetic thinking, and creative problem solving. Our first research question investigates whether this is true and whether it applies to different age groups of adolescents by scrutinizing the cognitive learning outcomes of the method. The second research question investigates the level of self-regulation skills and its relationship with cognitive learning outcomes. Finally, we scrutinize the motivation level of the learners during the geography course.

\subsection{Research questions and hypotheses}

We wanted to know how progressive inquiry affected the attainment of cognitive learning goals and motivation levels of learners. Motivation level is regarded as an affective learning ability. We also aimed to investigate the relationship between self-regulated learning skills and cognitive learning outcomes. Another study used qualitative interviews to examine what kinds of learning narratives existed among learners (Kuisma, 2018). In this study, we addressed the following research questions:

RQ1. Does progressive inquiry affect cognitive learning results when studying geography at different levels of the education system?

(1a) Does the progressive inquiry method affect cognitive learning results when studying geography?

(1b) Do the cognitive learning results differ between middle school and upper secondary school students when they are taught using the progressive inquiry method?

- RQ2. How do cognitive learning outcomes relate to self-regulated learning, specifically regulation of motivation?

RQ3. Does the progressive inquiry method affect the motivation levels of students?

First, we investigated if there was any statistically significant difference between the intervention group (progressive inquiry method and specific ICT) and control group's cognitive learning outcomes by testing the null hypothesis: $\mathrm{H}_{0}: \mathrm{CoLO}_{\text {Int }}=\mathrm{CoLO}_{\mathrm{Contr}}(\mathrm{CoLO}=$ Cognitive Learning Outcome; Int= Intervention group; Contr $=$ Control Group). We tested the data set of middle school students (Sample 1) and upper secondary school students (Sample 2) separately.

Second, we investigated the relationship between self-regulated learning skills, and teaching and learning methods with cognitive learning outcomes. We tested the null hypothesis, that there are no differences in variances between different groups of teaching and learning method, and levels of skills in self-regulated 
learning when investigated these groups' relations to post-test results. Additionally, we tested the null hypothesis $\mathrm{H}_{0}: \beta 1, \beta 2, \beta 3=0$ for the regression equation $\mathrm{CoLO}=\beta 0+\beta 1 * \mathrm{TLM}+\beta 2 * \mathrm{SRL}+\beta 3 * \mathrm{TLM} * \mathrm{SRL}$ $+\varepsilon(\mathrm{CoLO}=$ cognitive learning outcome as post-test score, $\beta 0=$ constant, TLM $=$ teaching and learning method, SRL $=$ self-regulated learning skills, $\varepsilon=$ random error).

Third, we investigated the effect of the progressive inquiry method on the level of motivation by null hypotheses that there are no differences in variances between different teaching and learning groups in motivation level. We investigated this matter at three different time points $\left(t_{0}, t_{1}\right.$, and $\left.t_{2}\right)$.

\section{Method}

\subsection{Participants}

All of the participants $(N=253)$ participated voluntarily, and their schools were located in an urban area in Central Finland. We sent out invitations via email to participate in this study to all the middle school and upper secondary geography teachers and head masters in Pirkanmaa region (area in Central Finland), and accepted all the volunteers. One hundred fifty-two informants (Sample 1) studied at the middle school of the comprehensive school, and 101 informants (Sample 2) studied at the upper secondary school. Middle school participants of this study took part in a course on the human and physical geography of Europe, the course topic for the upper secondary school students was geographical hazards.

Seventy-five students, among the younger participants of Sample 1, were part of the intervention group that studied using the progressive inquiry method and specific information and communication technology. Seventy-seven students were part of the control group that received teacher-centered training and a learning method that was different from ICT used in the intervention group. Students were taught by six different teachers in nine groups at two schools with an average group size of 18 students. Most (86.8\%) of the middle school students in Sample 1 were 14 years of age, and there were slightly more girls (55.3\%) than boys (44.7\%). The schools were homogeneous in terms of the students' school performance, and there were no statistically meaningful differences between the self-reported evaluations $\left(F_{1,150}=.926, p=.873\right)$. Furthermore, no classes required special admission criteria.

Forty-six students were part of the intervention group that studied with the progressive inquiry method and specific ICT in the upper secondary school in Sample 2, and 55 students were part of the control group that received teacher-centered teaching and a learning method that did not use specific ICT tools. They were taught by three different teachers at three different schools in five groups, with an average group size of 22 students. Sixty-two percent of the students were 17 years old, $16 \%$ were 18 years old, $13 \%$ were 16 years old, and $9 \%$ were 19 years old.

There were more male students (72.3\%) than females (27.7\%) among the upper secondary school participants. This shows that the voluntary course of geographical hazards attracted more boys than girls. There were no statistically significant differences between the students in the intervention and control groups in terms of academic success $\left(F_{1,99}=.028, p=.866\right)$. Furthermore, there were no statistically significant differences between the three different schools in terms of academic success $\left(F_{2,98}=1.446, p=.240\right)$.

The participants from the upper secondary school differed from the participants from the middle school because they chose to carry out their studies in this particular educational setting and were selected to attend the school based on their previous school performance. Therefore, the content and design of the geography courses differed between the middle and upper secondary schools. However, the intervention groups' progressive inquiry teaching and learning model was similar, and the way the intervention group used the ICT had similar objectives, even though developmental levels of the participants differed. 


\subsection{Research instruments}

The research instruments used in this study included self-report questionnaires and tests. The timeline of these instruments is displayed in Appendix 1. A pre-test and post-test were designed according to Bloom's taxonomy (Bloom, Hastings, \& Madaus, 1981) to measure the cognitive learning outcome. The tests had similar structures for both age groups, including 20 multiple choice questions that were designed to measure the students' recollection of factual knowledge (maximum score of 20 points), and five open-ended questions designed to measure the participants' understanding and abilities to apply, analyze, synthesize, and assess knowledge (maximum score of 10 points). The full upper secondary school pre-test is presented in Appendix 2. The multiple-choice questions are formulated according to the following example: "Which of the following concepts refer to an astronomical body that falls onto the surface of Earth? a. asteroid, b. comet, c. meteorite, d. shooting star." One example of the open-ended questions is as follows: "Compare the threats of volcanic eruptions and climate change. What differences are there in the nature of these threats?" A university teacher of geography didactics and two middle school and upper secondary school teachers assessed the tests. Finally, a pilot study was conducted with 21 middle and 18 upper secondary school students.

The means (and standard deviations) for the pre-test and post-test completed by the middle school participants were $22.4(S D=4.0)$ and $20.9(S D=5.3)$, respectively. The means (and standard deviations) for the pre-test and post-test completed by the upper secondary school participants were $19.0(S D=3.4)$ and 20.4 $(S D=3.4)$, respectively. The maximum score for the tests was 30 points, which assured that the items were challenging without being excessively difficult.

For the middle school participants in Sample 1 ( $n=152)$, the Cronbach's coefficients were $\alpha=.76$ for the pre-test and $\alpha=.84$ for the post-test. This ensured that the tests were reliable. For the upper secondary school participants in Sample $2(n=101)$, the Cronbach's coefficients were $\alpha=.56$ for the pre-test and $\alpha=.63$ for the post-test.

Regulation of motivation was measured with a 31-item survey developed by Wolters and his colleagues (Wolters, Pintrich, \& Karabenick, 2003; Wolters \& Benzon, 2013). It extends previous instruments (e.g., MSLQ, Pintrich, Smith, Garcia, \& McKeachie, 1993) by focusing on (Wolters, 2003, p. 190) "the activities through which individuals purposefully act to initiate, maintain, or supplement their willingness to start, to provide work toward, or to complete a particular activity or goal (i.e., their level of motivation)." The instrument investigates motivation regulation with six dimensions: 1) Regulation of value; 2) Regulation of performance goals; 3) Self-consequating; 4) Environmental structuring; 5) Regulation of situational interest; 6) Regulation of mastery goals. Students responded to the survey with a five-point Likert scale (1=Totally disagree, $\ldots, 5=$ Totally agree). A sample item from the Self-consequating factor is as follows: "I make a deal with myself that if I get a certain amount of the work done I can do something fun afterwards." According to Wolters and Benzon (2013), bivariate correlations among six motivation regulation strategies have shown to be positive and fairly strong (.15-.75). In this study, a summative scale was calculated for the 31 items and discretized into five classes (Weak, Sufficient, Satisfactory, Good, Excellent, see Table 1 for details) in order to group students based on their motivational regulation. The reliability of the 31 variables was high in both samples (Sample 1, $\alpha=.95$; Sample 2, $\alpha=.94$ ). This indicates that all the variables measure the same construct, strategies for the regulation of motivation.

The learners self-assessed their levels of motivation on a five-point Likert scale (1=Totally disagree, $\ldots, 5=$ Totally agree) at three time points: at the beginning $\left(\mathrm{t}_{0}\right)$, in the middle $\left(\mathrm{t}_{1}\right)$, and at the end $\left(\mathrm{t}_{2}\right)$ of the geography course. Items were derived from Pedagogically Meaningful Learning Questionnaire (PMLQ, Nokelainen, 2006) that was originally designed to measure experiences on the ten categories of learning connected to the usability of learning material: 1) Learner control; 2) Learner activity; 3) Collaborative learning; 4) Goal orientation; 5) Applicability in other contexts; 6) Added value of the learning method; 7) Motivation; 8) Valuation of previous knowledge; 9) Flexibility in certain time points during the investigation period; 10) Feedback. In this study, only category for the motivation was applied. It is based on MSLQ (Pintrich, Smith, Garcia, \& McKeachie, 1993) and measures dimensions of intrinsic goal orientation, extrinsic goal orientations and meaningfulness of studies with four items. These items were summarized into one 
summative motivation variable. One example of these items is as follows: "The topics to be learnt at school are interesting to me." The first measurement $\left(\mathrm{t}_{0}\right)$ took place in the first lesson of the geography course. The second measurement $\left(\mathrm{t}_{1}\right)$ was done after the first digital game took place in the intervention groups; and the third measurement $\left(\mathrm{t}_{2}\right)$ took place after the second digital game (Sample 1, middle school) or after the interactive leaflet was finished (Sample 2, upper secondary school). Based on the time point, the Cronbach's alpha varied from .55 to .68 (Sample 1, middle school) and .63 to .72 (Sample 2, upper secondary school).

\subsection{Procedures}

The rationale for this quasi-experimental study was sent to the Ethics Committee of the Tampere Region for revision. The committee approved this investigation as planned. All of the students answered the pre-tests at the beginning of the course and completed the post-test at the end of the course. They also filled in a self-report survey about their strategies for the regulation of motivation during their first lesson. Furthermore, a survey measuring their motivational level was filled out at the beginning, in the middle, and at the end of the course.

\subsubsection{Instruction for middle school participants in the intervention group}

The researcher and teachers jointly planned the events in the geography course, and the subject was the human and physical geography of Europe. The events of the intervention group were designed to take place as follows: The teacher presented the outline of the course, including its main contents, objectives, and assessments. Then, each student was asked to choose a European country for his or her project work, and the students with the same country formed a pair. Next, each pair wrote down what they already knew about the country and why they chose it, and were asked to develop a study plan including research questions to be answered. The digital learning platform, Moodle, was used to write the study plans, comment on them, ask questions, and disseminate the best information sources with peers. The project work proceeded progressively by searching for information and seeking answers to the questions in the study plan and inventing new questions. The project also involved drawing maps for certain geographical topics, such as topography and livelihoods, and writing down how the map related to other maps and phenomena.

In addition to their progressive investigation, the adolescents were asked to design simple digital games for their peers on two different topics. Their peers then played each game by solving the geographical dilemmas. The teacher used an interactive whiteboard during the geography course, and the students used it when playing the interactive game. The task of the first game was to design a pair of vortexes for two different types of weathering (e.g., physical and chemical weathering), and in the second game to design a vortex pair for two types of climate (e.g., Mediterranean and subarctic climate).

At the end of the course, a tourism fair was organized in the classroom. Half of the student pairs played the role of experts advertising their country to visitors, and then they switched roles. The maps and diagrams were presented at the fair along with drawings, pictures, and souvenirs that the students chose to display. The students were then asked to compare their original study plans with the outcomes of their work in order to make the learning visible.

\subsubsection{Instruction for upper secondary participants in the intervention group}

The researcher and teachers jointly planned the events in the geography course. The subject of the course was geographical hazards in the field of human and physical geography. The events for the intervention group were designed to take place as follows: The teacher presented the outline of the course, including the main contents, objectives, and assessment. Then, each student was asked to choose one geographical hazard for his or her project, and the students with the same hazards formed a pair. Next, each pair wrote down what they already knew about the hazard and why they chosen it, and developed a study plan with research questions. The digital learning platform, Moodle, was used to write the study plans, comment on them, ask questions, and disseminate the best information sources to peers. The project would proceed progressively, 
starting with searching for information, followed by seeking answers to the questions in the study plan, and finally inventing new questions.

The project work involved drawing at least one picture of the hazard, and adding augmented reality in the form of a video clip or audio file to the drawing. Each pair wrote a report about their hazard and attached a drawing that including augmented reality. Finally, an interactive leaflet was created with the various hazards, which supported the students when studying for the exam.

In addition to their progressive investigation, the adolescents designed a simple digital game for their peers about two climatic hazards (climate change and ozone depletion). Their peers played each game by solving the geographical dilemmas. The teacher used an interactive whiteboard during the geography course, and the students used it when playing the interactive game.

At the end of the course, each pair gave a presentation of their work and displayed their videos or other supplementary material. The students used tablet computers; therefore, they used the technology that was attached to their devices to present their work. Finally, the students were asked to compare their original study plans with the outcomes of their projects in order to make the learning visible.

\subsubsection{Instruction for the control groups}

The teacher presented the outline of the course, including its main contents, objectives, and assessments. Then, the teacher introduced each topic, followed by exercises that were executed individually or with a peer. The students did not complete a project on a specific topic throughout the entire course. Moreover, they did not use a digital learning platform, such as Moodle, for planning or disseminating their ideas or information sources. They did not design a digital game in pairs, and the upper secondary school participants did not create a leaflet. In other words, the students in the control groups were not guided to work collaboratively to the same extent as the students in intervention group. Moreover, they did not have the same autonomy in their learning exercises, which meant they received more teacher-centered instruction without as many technological tools. The most important difference when compared to the intervention groups is that these learners did not follow the question-driven procedure of the progressive inquiry model and they did not use educational technology tools to implement the collaborative studying approach into practice.

\subsection{Data analyses}

All of the data analyses were executed with SPSS, and the numeric data was systematically observed for outlier detection. In middle school data set, both the pre-test and post-test scores were skewed toward the high end of scale, whereas in the upper secondary school data set, the distribution of the pre-test was normal and the post-test score showed high kurtosis and was slightly skewed toward high scores. Nevertheless, the skewed values were below one; therefore, the distributions were considered close enough to normal for parametric tests to be applied.

\section{Results}

\subsection{RQ1: Effects of the teaching and learning model on cognitive outcomes}

The following phrasing was used when presenting the results: The intervention groups comprised students who studied with progressive inquiry and specific ICT tools, as described in Chapters 2.3.1 and 2.3.2, whereas students in the control groups received teacher-centered instruction, as described in Chapter 2.3.3. The middle school students in the intervention and control groups scored similar results on the pre-test $(t=-$ $.647, d f=150, p=.519)$ and Levene's test for homogeneity of variances indicated equal variances $(F=.152$, $p=.697)$. The middle school students in the intervention group scored higher points $(M=22.0, S D=4.4)$ on 
the post-test compared to the control group $(M=19.4, S D=6.1)$. An independent samples $t$-test was executed to investigate the statistical significance between these mean values. The difference was statistically significant $(t=3.0, d f=139, p=.003)$. According to Levene's test, the difference between the variances in the intervention and control groups was statistically significant $(F=10.0, p=.002)$. The deviation in the post-test score was higher in the control group $(S D=6.1)$ than in the intervention group $(S D=4.4)$.

Similarly, there were no statistically significant differences in the pre-test scores between the upper secondary students in the intervention and control groups $(t=-1.413, d f=99, p=.161)$, and Levene's test indicated equal variances $(F=1.207, p=.255)$. The students in the intervention group scored statistically higher points $(M=21.4, S D=2.9)$ on the post-test compared to students in the control group $(M=19.6, S D=$ $3.6, t=2.761, d f=99, p=.007)$. The equal variances were assumed based on Levene's test $(F=1.016, p=$ $.316)$.

The gain value was calculated based on the original pre-test and post-test scores because it normalized the progress in the learning outcome results. For example, when a student who scored high points on the pretest, scored high points once again on the post-test, they did not receive the highest points of improvement. The absolute gain value $(G)$ was calculated as $G=$ Posttest $\%$ - Pre-test $\% / 100 \%$-Pre-test $\%$. In other words, the gain value measured students' improvement between the pre-test and post-test. In this sample, the variance in the gain values was tested by applying the Mann-Whitney $U$-test to the nonparametric independent samples because of the skewed values and high kurtosis in the distribution of the variables.

Mann-Whitney $U$-test was used to examine the difference between the gain values of the middle school and the upper secondary school intervention and control groups. Results showed a statistically significant difference $(p<.0001)$ in absolute gain values between intervention group $(M=-0.15, S D=.65)$ and control group $(M=-0.59, S D=1.15)$ among middle school students. Similar result was also found from the upper secondary school sample (intervention group: $M=0.22, S D=.31$; control group: $M=-0.03, S D=$ .34). This indicates that in both samples the intervention group students' cognitive geographical skills improved more than of those in the control group.

\subsection{RQ2: Relationships between regulation of motivation and cognitive learning outcomes}

A summative variable was constructed from the score that was derived from the 31 variables measuring strategies for the regulation of motivation. As the observations of the original variable were normally distributed $(N=253, M=127.9, S D=27.5, M d n=129, M o=129)$, it was decided to reconstruct five groups of equal relative frequencies. The group in the middle included the mean, median, and mode values (Table 1). The variable of different teaching and learning groups in different educational levels was recoded into a new dummy variable, where a value of 1 equaled the progressive inquiry and a value 0 equaled the teacher-centered approach.

Table 1

Relative frequencies of motivation regulation skills in five categories $(N=253)$

\begin{tabular}{|l|c|c|}
\hline $\begin{array}{l}\text { Score of strategies } \\
\text { for the regulation } \\
\text { of motivation, in } \\
\text { points }\end{array}$ & $\begin{array}{l}\text { Relative frequency, } \\
\%\end{array}$ & $\begin{array}{l}\text { Labeling of the } \\
\text { motivation regulation } \\
\text { level }\end{array}$ \\
\hline$\leq 107$ & 19.2 & Weak \\
\hline $108-127$ & 19.6 & Sufficient \\
\hline $128-134$ & 19.2 & Satisfactory \\
\hline $135-151$ & 20.0 & Good \\
\hline$\geq 152$ & 18.0 & Excellent \\
\hline
\end{tabular}


We tested the null hypothesis that there were no differences in the variances between the different groups of teaching and learning methods, and the levels of self-regulated learning skills when investigated these groups' relations to post-test results in both samples. In Sample 1 (middle school), Levene's test showed that the error variance of the dependent variable (post-test score) was equal across the investigated groups $\left(F_{9}\right.$, $\left.{ }_{141}=1.813, p=.071\right)$, and the results from the regression analysis suggested that in this model $\left(\mathrm{CoLO}=\beta_{0}+\right.$ $\beta_{1} * \mathrm{TLM}+\beta_{2} * \mathrm{SRL}+\beta_{3} * \mathrm{TLM} * \mathrm{SRL}+\varepsilon ; \mathrm{CoLO}=$ cognitive learning outcome as post-test score, TLM $=$ teaching and learning method, SRL = self-regulated learning skills), the teaching and learning methods did not explain the post-test score $\left(F_{1,141}=3.866, p=.121\right)$ in a statistically significant way. Neither the self-regulated learning skills alone $\left(F_{4,141}=.329, p=.847\right)$ nor scrutinized together with the teaching and learning method $\left(F_{4,141}=2.148, p=.078\right)$ had any statistically significant relationship with the post-test score. The ANOVA showed that the teaching and learning models explained only a part of the success on the post-test $\left(\eta^{2}=.056\right.$, $p=.005)$, while self-regulated learning skills explained even less $\left(\eta^{2}=.020, p=.589\right)$.

In Sample 2 (upper secondary school), Levene's test showed that the error variance of the dependent variable (post-test score) was equal across the investigated groups $\left(F_{9,89}=1.714, p=.097\right)$. The results of the regression analysis suggested that in this model $\left(\mathrm{CoLO}=\beta_{0}+\beta_{1} * \mathrm{TLM}+\beta_{2} * \mathrm{SRL}+\beta_{3} * \mathrm{TLM} * \mathrm{SRL}+\varepsilon\right)$ the teaching and learning methods explained the post-test score $\left(F_{1,89}=13.367, p=.017, \eta^{2}=.74\right)$ in a statistically significant way. Neither the self-regulated learning skills alone $\left(F_{4,89}=1.088, p=.468, \eta^{2}=.52\right)$ nor scrutinized together with the teaching and learning methods $\left(F_{4,89}=.641, p=.634, \eta^{2}=.03\right)$ had any statistically significant explanatory effect on the post-test score. The ANOVA suggested that this model failed to explain much of the variation in the post-test scores because the teaching and learning methods explained only some of the success on the post-test $\left(\eta^{2}=.090, p=.004\right)$, and self-regulated learning skills explained even less $\left(\eta^{2}=.030, p=\right.$ $.596)$.

Even though the differences between the variances were not statistically significant, Figure 1 shows how the post-test scores were higher among the middle school students with weak, sufficient, satisfactory, or good self-regulation skills, when the progressive inquiry method was used. Students with high self-regulation skills scored slightly higher points on the post-test when they received teacher-centered instruction. Additionally, Figure 1 shows that among upper secondary school students, the post-test scores were higher for every level of self-regulation skills when the progressive inquiry method was used.

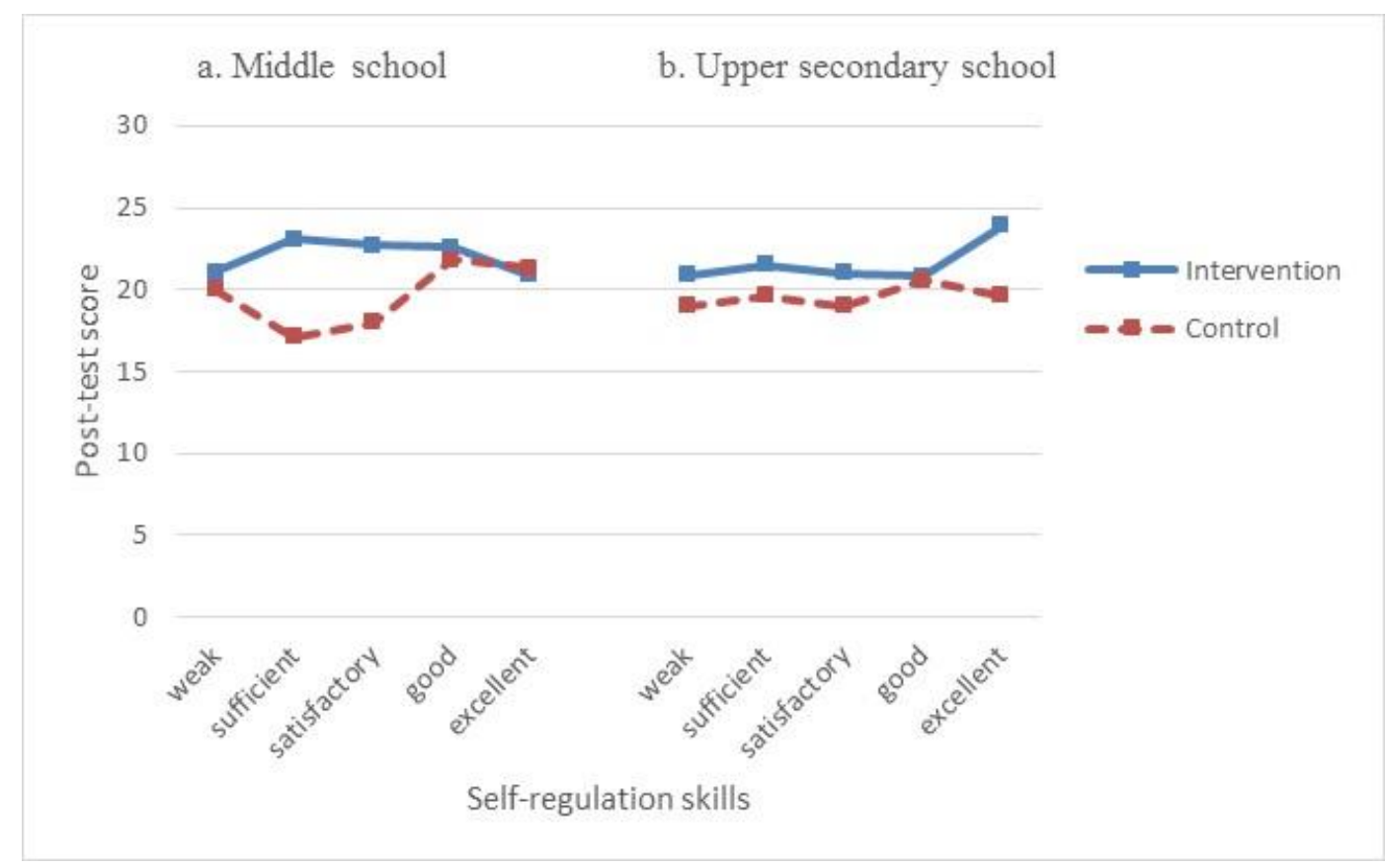


Figure 1. Self-reported self-regulation skills in relation to post-test scores in the intervention and control groups at both education levels.

\subsection{RQ3: Relationship between the level of motivation and the teaching and learning methods}

In Sample 1 (middle school), Levene's test showed that the error variance of the dependent variable (level of motivation) was equal across the middle school students in the investigated groups ( $\mathrm{t}_{0}: F_{1,150}=1.056$,

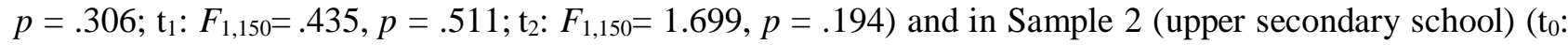
$\left.F_{1,99}=.36, p=.549 ; \mathrm{t}_{1}: F_{1,99}=.003, p=.958 ; \mathrm{t}_{2}: F_{1,99}=4.838, p=.030\right)$. In the upper secondary school sample, the last measuring point $\left(\mathrm{t}_{2}\right)$ showed that equal variances could not be assumed between the intervention and control groups. This should be recognized when interpreting the results.

When analyzed using Wilks' Lambda test, the results showed that the motivation level did not differ in a statistically significant way between the different time points (Sample 1, $p>.05$; Sample 2, $p>.05$ ); however, it did differ in a significant way between the teaching and learning models used with the middle school $\left(F_{1,150}=7038.8, p<.0001\right)$ and upper secondary school $\left(F_{1,99}=5859.8, p<.0001\right)$ students. In both samples, the teaching and learning models explained most of the variation in the students' motivation levels $\left(\eta^{2}=.98\right)$. Figure 2 visualizes the motivation levels at three different time points.

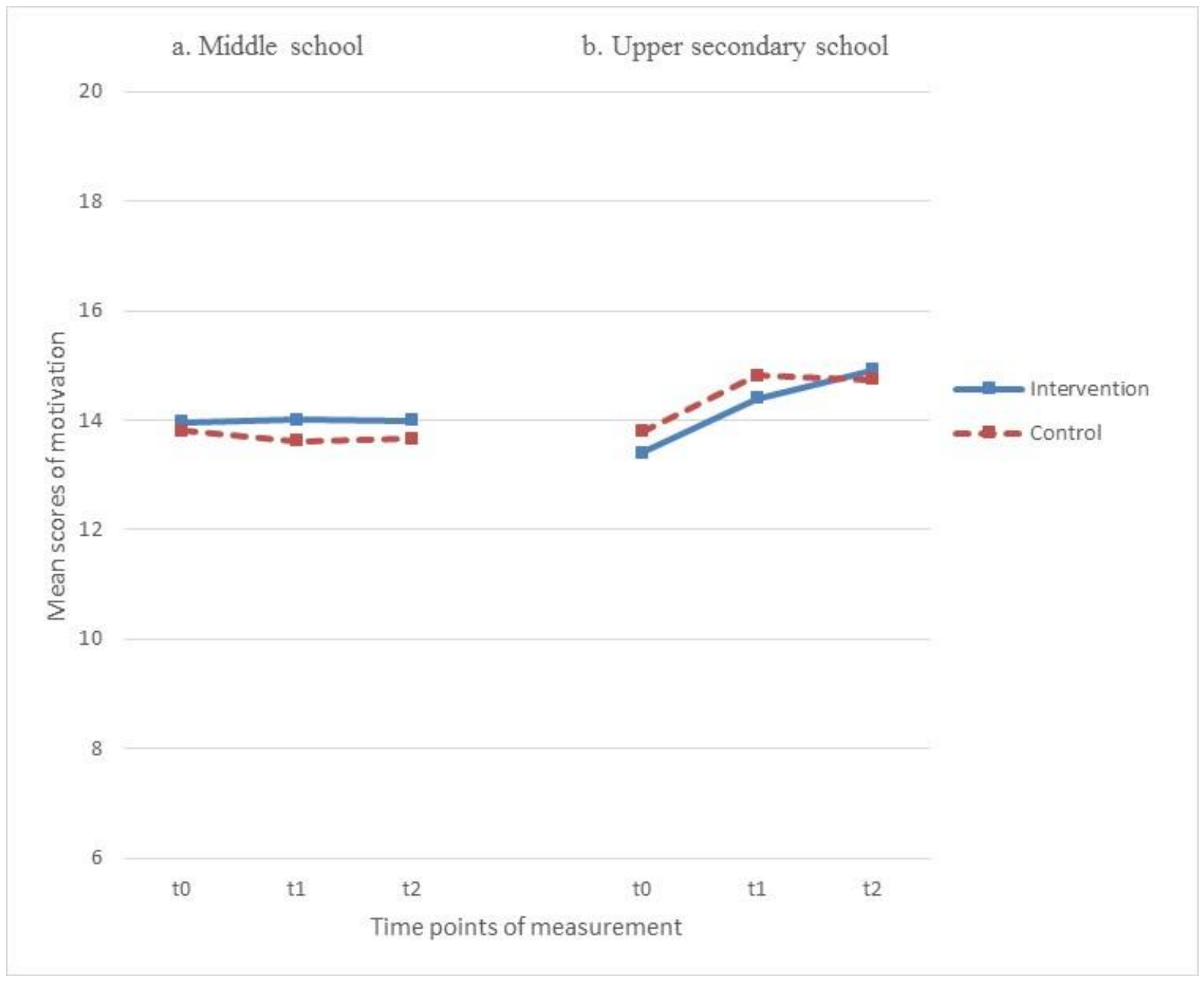

Figure 2. Self-reported motivation levels in the intervention groups that used the progressive inquiry learning model compared to the control groups, which received teacher-centered instruction in middle school and upper secondary schools (measured at time points $\mathrm{t}_{0}, \mathrm{t}_{1}$, and $\mathrm{t}_{2}$ ). 


\section{Discussion and conclusions}

According to this study, the progressive inquiry learning model fits well with geographical studies both at the middle and upper secondary school levels. When investigating RQ1, the students at both educational levels showed higher post-test scores when taught with the progressive inquiry method, and their cognitive learning outcomes improved significantly more than the control group. As the skills to analyze data and make syntheses were also being measured in pre- and post-tests, the results suggest that this type of progressive inquiry teaching and learning model, which enhances the higher-order thinking skills, fits well both education levels. This result was in line with previous research on computer-supported collaborative learning (CSCL), which suggests that CSCL technologies trigger positive changes in group dynamics by enhancing learning interactions and enabling sharing and constructing knowledge among team members (Ludvigsen, Lund, Rasmussen, \& Säljö, 2011). It was also congruent with the finding that learning complex and challenging science topics improves when students are repeatedly trained to use their self-regulatory skills in hypermedia environments (Greene \& Azevedo, 2007). Since collaborative learning has become more common (O'Donnell \& Hmelo-Silver, 2013), research on engagement in learning has broadened from the context of individual learning to collaborative groups (Järvelä, Järvenoja, Malmberg, Isohätälä, \& Sobocinski, 2016). We require more information on the cognitive and socio-emotional interactions between team members in order to support different kind of learners, and the ways that self-, co-, and socially shared regulation affect the collaborative learning process.

Furthermore, this study provided evidence that supported the following claim: since students in upper secondary school are older and have undergone a selection procedure to attend the school, it is understandable that the progressive inquiry method would suit them better than younger students because their self-regulated learning skills would be more developed. This conclusion is derived from upper secondary school students' higher absolute gain values, as well as the higher probability that the gain values would differ between the group that studied using the progressive inquiry method and the group that received teacher-centered instruction.

The results from RQ2 suggested that the self-regulated learning skills that the student possessed before the course did not affect their cognitive learning outcome in a statistically significant way in either the middle or upper secondary schools. This meant that the students were able to attain the necessary self-regulation skills during the course, and students with poorer self-regulated learning skills had equal possibilities to succeed when either the progressive inquiry method or teacher-centered method was applied. There was an interesting tendency suggesting that middle school students with the strongest self-regulatory learning skills scored the highest points on the post-test when they received teacher-centered instruction. The result was not statistically significant, but it would be useful to investigate, whether the students with a high level of self-regulation skills do not benefit from the progressive inquiry method as much as students with weaker self-regulation skills.

It would be useful to measure students' self-regulated learning skills in terms of regulation of motivation at the end of the course as well, in order to get more insight about whether the progressive inquiry method enhances these skills. However, since the progressive inquiry method enhances student autonomy when making choices about the order of tasks, proceeding with tasks, or scheduling their studies (Kuisma, 2018), good results in cognitive learning outcomes point to potential improvement in these learning outcomes as well. This finding is in line with Wolters and Benzon (2013, p. 218) as they state that "efforts to improve students' self-regulated learning may benefit from including motivational strategies into the instructional plan." In future studies, we intend to use six factor structure of motivation regulation instead of a summative score, as Wolters and Benzon (2013) concluded after their empirical study that correlations of motivation regulation factors were not substantial enough to indicate a single underlying construct.

The results from RQ3 clearly show the positive effect of the progressive inquiry method on learners' motivation levels in middle school. Wolters and Pintrich (1998) found in their study that students' motivation level varied across several disciplines (mathematics, social studies, and English), but not their regulatory 
strategy use. Although current study had no variance in discipline and did not measure change in regulatory processes, motivation levels were higher throughout the geography course compared to the control group. The collaborative activities in the form of designing and playing the digital games, along with the progressing project work, seemed to increase the motivation level of the middle school students. However, in the upper secondary school, the motivation levels of the intervention group were lower than those of the group that received teacher-centered training. The motivation levels of the intervention group continued to rise from one time point to another. Finally, the motivation levels at the end of the course rose to the same levels as the control group. Altogether, the upper secondary school students seemed to be less motivated by the progressive inquiry method than the younger students.

Inquiry learning can be used in classroom practices with or without ICT, but it has been shown that learners' abilities for scientific research and collaboration skills are fortified when ICT is included (Banchi \& Bell, 2008; Hakkarainen et al., 2004). It has been suggested that the gap between the every-day use of ICT and the way it is utilized at school can affect students' motivation in higher education (Hietajärvi et al., 2015). Although socio-digital participation has proven to be a tangled web of relationships, it is suggested that complex technology-mediated knowledge practices can be useful for learning in educational settings when striving for deep learning. It would be interesting to investigate this web of causal relationships among middle and secondary school students.

\section{Keypoints}

- The progressive inquiry method and learning model suits geography education because it improved students' cognitive learning outcomes and motivation levels.

- Cognitive learning outcomes were improved at both education levels, i.e., middle school and upper secondary school.

- Upper secondary school students profited more from the progressive inquiry method in terms of cognitive outcomes compared to middle school students.

- Previous self-regulated learning skills had no effect on cognitive outcomes; therefore, the necessary regulation skills could be adopted during the course.

- The positive effect on motivation levels was evident in the middle school context.

\section{References}

Banchi, H., \& Bell, R. (2008). The many levels of inquiry. Science and children, 46(2), 26-29.

Bereiter, C. (2002). Education and mind in the knowledge age. Hillsdale, NJ: Erlbaum.

Bloom, B. S., Hastings, J. T., \& Madaus, G. F. (Eds.) (1981). Evaluation to improve learning. New York, NY: McGraw-Hill Inc.

Cerratto-Pargman, T., Järvelä, S. M., \& Milrad, M. (2012). Designing Nordic technology-enhanced learning. Internet \& Higher Education, 15(4), 227-230. doi:10.1016/j.iheduc.2012.05.001

Dimitrov, D. M., \& Rumrill, P. D. (2003). Pre-test-posttest designs and measurement of change. Assessment \& Rehabilitation, 20(2), 159-165.

Greene, J. A., \& Azevedo, R. (2007). Adolescents' use of self-regulatory processes and their relation to qualitative mental model shifts while using hypermedia. Journal of Educational Computing Research, 36(2), 125-148. Retrieved from https://doi-org.helios.uta.fi/10.2190/G7M1-2734-3JRR-8033 
Engeström, Y. (1999). Innovative learning in work teams: Analyzing cycles of knowledge creation in practice. In Y. Engeström, R. Miettinen, \& R.-L. Punamäki (Eds.), Perspectives on activity theory (pp. 377-404). Cambridge, UK: Cambridge University Press.

Finnish National Board of Education. (2015). Curriculum reform 2016. Retrieved from http://www.oph.fi/english/current_issues/101/0/what_is_going_on_in_finland_curriculum_reform_2016

Hakkarainen, K. (2009). A knowledge-practice perspective on technology-mediated learning. ComputerSupported Collaborative Learning, 4, 213-231. doi:10.1007/s11412-009-9064-x

Hakkarainen, K., Palonen, T., Paavola, S., \& Lehtinen, E. (2004). Communities of networked expertise: Professional and educational perspectives. Amsterdam, Netherlands: Elsevier.

Hietajärvi, L., Tuominen-Soini, H., Hakkarainen, K., Salmela-Aro, K., \& Lonka, K. (2015). Is student motivation related to socio-digital participation? A person-oriented approach. Procedia - Social and Behavioral Sciences, 171, 1156-1167. doi:10.1016/j.sbspro.2015.01.226

Hintikka, J. (1982). A dialogical model of teaching. Synthese, 51(1), 39-59.

Hintikka, J. (1985). True and false logic of scientific discovery. In J. Hintikka \& F. Vandamme (Eds.), Logic of discovery and logic of discourse (pp. 3-14). New York, NY: Plenum Press.

Järvelä, S., \& Hadwin, A. F. (2013). New frontiers: Regulating Learning in CSCL. Educational Psychologist, 48(1), 25-39. doi:10.1080/00461520.2012.748006

Järvelä, S., Järvenoja, H., Malmberg, J., Isohätälä, J., \& Sobocinski, M. (2016). How do types of interaction and phases of self-regulated learning set a stage for collaborative engagement? Learning and Instruction, 43, 39-51. doi:10.1016/j.learninstruc.2016.01.005

Kuisma, M. (2018). Narratives of Inquiry Learning in Middle School Geographic Inquiry Class. International Research in Geographical and Environmental Education, 27(1), 85-98. doi:10.1080/10382046.2017.1285137 Leat, D. (1997). Cognitive acceleration in geographical education. In M. Williams \& D. Tilbury (Eds.), Teaching and learning geography (pp. 143-153). London, UK: Routledge.

Leat, D. (1998). Thinking through geography. Cambridge, UK: Chris Kington Publishing.

Le Deist, F. D., \& Winterton, J. (2005). What is Competence? Human Resource Development International, 8(1), 27-46. doi: $10.1080 / 1367886042000338227$

Loyens, S. M. M., Magda, J., \& Rikers, R. M. J. (2008). Self-Directed Learning in Problem-Based Learning and its Relationships with Self-Regulated Learning. Educational Psychology Review, 20(4), 411-427. doi: 10.1007/s10648-008-9082-7

Ludvigsen, S., Lund, A., Rasmussen, I., \& Säljö, R. (Eds.) (2011). Learning across sites. New tools, infrastructures and practices. Oxford, UK: Routledge.

Muukkonen, H., Hakkarainen, K., \& Lakkala, M. (1999, December 12-15). Collaborative technology for facilitating progressive inquiry: Future learning environment tools. In C. Hoadley \& J. Roschelle (Eds.), Proceedings of the Computer Support for Collaborative Learning (CSCL) 1999 Conference. Stanford University, Palo Alto, California. Mahwah, NJ: Lawrence Erlbaum Associates.

Nagel, P. (2008). Geography: The essential skill for the $21^{\text {st }}$ century. Social Education, 72(7), 354-358. Retrieved from https://www.socialstudies.org/publications/socialeducation/novemberdecember2008/geography-the-essential-skill-for-the-21st-century

Nokelainen, P. (2006). An empirical assessment of pedagogical usability criteria for digital learning material with elementary school students. Educational Technology \& Society, 9(2), 178-197. Retrieved from https://pdfs.semanticscholar.org/ea96/b628f440642d72026c14710a67ccd06f41f1.pdf

Nokelainen, P., Kaisvuo, H., \& Pylväs, L. (2016). Self-regulation and competence in work-based learning. In M. Mulder (Ed.), Competence-based Vocational and Professional Education. Bridging the Worlds of Work and Education: Bridging the Worlds of Work and Education. (pp. 775-793). Dortrecht: Springer. doi:10.1007/978-3-319-41713-4_36

Nonaka, I., \& Takeuchi, H. (1995). The knowledge-creating company: How Japanese companies create the dynamics of innovation. New York, NY: Oxford University Press.

O’Donnell, A. M., \& Hmelo-Silver, H. E. (2013). What is collaborative learning: An overview. In C. E. HmeloSilver, C. A. Chinn, C. K. K. Chan, \& A. O'Donnell (Eds.), The International handbook of collaborative learning (pp. 1-15). New York: Routledge. 
Paavola, S., \& Hakkarainen, K. (2005). The knowledge creation metaphor: An emergent epistemological approach to learning. Science \& Education, 14(6), 535-557. doi: 10.1007/s11191-004-5157-0

Pauw, I. (2015). Educating for the future: The position of school geography. International Research in Geographical and Environmental Education, 24(4), 307-324. doi: 10.1080/10382046.2015.1086103

Pintrich, P. R. (1999). The role of motivation in promoting and sustaining self-regulated learning. International Journal of Educational Research, 31(6), 459-470. doi:10.1016/S0883-0355(99)00015-4

Pintrich, P. R. (2004). A conceptual framework for assessing motivation and self-regulated learning in college students. Educational Psychology Review, 16(4), 385-407. http://doi.org/10.1007/s10648-004-0006-x

Pintrich, P. R., Smith, D., Garcia, T., \& McKeachie, W. J. (1993). Reliability and Predictive Validity of the Motivated Strategies for Learning Questionnaire (MSLQ). Educational \& Psychological Measurement, 53(3), 801-813. doi:10.1177/0013164493053003024

Prince, M. J., \& Felder, R. M. (2006). Inductive teaching and learning methods: Definitions, comparisons, and research bases. Journal Of Engineering Education, 95(2), 123-138.

Scardamalia, M. (2002). Collective cognitive responsibility for the advancement of knowledge. In B. Smith (Ed.), Liberal education in a knowledge society (pp. 67-98). Chicago, IL: Open Court.

Scardamalia, M., \& Bereiter, C. (1994). Computer support for knowledge-building communities. The Journal of the Learning Sciences, 3, 265-283. Retrieved from http://www.jstor.org/stable/1466822

Winne, P. H. (1995). Self-regulation is ubiquitous but its forms vary with knowledge. Educational Psychologist, 30, 223-228.

Wolters, C. A. (2003). Regulation of motivation: Evaluating an underemphasized aspect of self-regulated learning. Educational Psychologist, 38, 189-205.

Wolters, C. A., \& Benzon, M. B. (2013). Assessing and Predicting College Students' Use of Strategies for the Self-Regulation of Motivation. The Journal of Experimental Education, 81(2), 199-221. doi: 10.1080/00220973.2012.699901

Wolters, C. A., \& Pintrich, P. R. (1998). Contextual differences in student motivation and self-regulated learning in mathematics, English, and social studies classrooms. Instructional Science, 26, 27-47.

Wolters, C. A., \& Taylor D. J. (2012). A Self-regulated Learning Perspective on Student Engagement. In S. L. Christenson, A. L. Reschly, \& C. Wylie (Eds.), Handbook of Research on Student Engagement (pp. 635651). Boston, MA: Springer.

Wolters, C. A., Pintrich, P. R., \& Karabenick, S. A. (2003, April). Assessing academic self-regulated learning. Paper presented at the Conference on Indicators of Positive Development: Definitions, Measures, and Prospective Validity, ChildTrends, Bethesda, MD.

Zimmerman, B. J. (1998). Academic Studying and the Development of Personal Skill: a Self-Regulatory Perspective. Educational Psychologist, 33(2/3), 73-86.

Zimmerman, B. J. (2000). Self-efficacy: an essential motive to learn. Contemporary Educational Psychology, 25(1), 82-91. doi:10.1006/ceps.1999.1016

Zimmerman, B. J., \& Schunk, D. H. (2008). Motivation: An Essential Dimension of Self-Regulated Learning. In D. H. Schunk, \& B. J. Zimmerman (Eds.), Motivation and Self-Regulated Learning: Theory, Research, and Applications (pp. 1-30). Mahwah, NJ: Erlbaum. 


\section{Appendix 1}

Research design

\begin{tabular}{|c|c|c|c|c|}
\hline \multicolumn{5}{|c|}{ Geography of Europe / Geographical Hazards } \\
\hline Intervention group 1 & \multicolumn{2}{|c|}{$\begin{array}{l}\text { Progressive inquiry: learner- } \\
\text { centered }\end{array}$} & \multicolumn{2}{|l|}{$n=75$} \\
\hline Control group 1 & \multicolumn{2}{|c|}{ Teacher-centered } & \multicolumn{2}{|l|}{$n=77$} \\
\hline Intervention group 2 & \multicolumn{2}{|c|}{$\begin{array}{l}\text { Progressive inquiry: learner- } \\
\text { centered }\end{array}$} & \multicolumn{2}{|l|}{$n=46$} \\
\hline Control group 2 & \multicolumn{2}{|c|}{ Teacher-centered } & \multicolumn{2}{|l|}{$n=55$} \\
\hline & $\begin{array}{l}\mathrm{t}_{0} \\
\text { Pre-test } \\
\text { Regulation of } \\
\text { motivation survey } \\
\text { Motivational level } \\
\text { survey }\end{array}$ & \multicolumn{2}{|c|}{$\begin{array}{l}\mathrm{t}_{1} \\
\text { Motivational level } \\
\text { survey }\end{array}$} & $\begin{array}{l}\mathrm{t}_{2} \\
\text { Motivational level } \\
\text { survey } \\
\text { Post-test }\end{array}$ \\
\hline
\end{tabular}

Group 1: Sample 1, Middle school students

Group 2: Sample 2, Upper secondary school students

\section{Appendix 2}

\section{Pre-test in upper secondary school}

Circle the option that you think is correct. (Only one of the options is correct!)

1. Which of the following concepts refer to an astronomical body that falls onto the surface of Earth?
a. asteroid
b. comet
c. meteorite
d. shooting star

2. During the sunspot cycle when the Sun is the most active,

a. Earth's magnetic field changes, so that a magnetic storm may destroy transformers, electronic devices and satellites.

b. the movement of tectonic plates strengthens and volcanic activity causes threats to human activities.

c. the slowing down of sea currents may cause global warming.

d. the ozone layer in the upper atmosphere thins down significantly.

3. How large a portion of all earthquakes on Earth take place in the Pacific Ocean and its surrounding areas? 

a. $10 \%$
b. $25 \%$
c. $50 \%$
d. $80 \%$

4. Loss of human lives caused by earthquakes can be decreased

a. by building a large undivided space under an apartment building, e.g. a parking hall.

b. by making large buildings as complex in shape as possible.

c. by attaching the floors of apartment buildings (ceilings) properly to the building's load-bearing walls by using steel reinforcement structures.

d. by decreasing the use of adjusting structures.

5. A tsunami usually begins from an earthquake which

a. is caused by an asteroid crash.

b. is caused by human activities, e.g. building of dams.

c. takes place in the inner parts of the continental lithosphere plate.

d. raises the water mass above the whole earthquake area, causing a giant wave advancing in all directions.

6. The magnitude of an explosive volcanic eruption depends on
a. the composition of magma.
b. the steepness of the volcano's slope.
c. population density on the slopes of the volcano.
d. the location of the area with respect to the equator.

7. Volcanic activity is useful to local people because

a. geysers and craters attract tourists.

b. a volcano that has erupted once will not erupt a second time, and it is possible to build a tourist resort in the crater.

c. the volcanic mud slides from volcanos would make a luxurious spa treatment for tourists.

d. it is easy to predict volcanic eruptions, and volcano eruption watching attracts tourists.

8. How does a cyclone form?

a. It is formed when strong winds combine together.

b. It is formed from warm seawater from a strong low pressure area.

c. It is formed when a rain front approaching from the sea meets a continent.

d. It is formed when a tsunami meets a continent.

9. Which of the following countries have suffered the most from tropical cyclones?
a. Japan
b. Bangladesh
c. United States
d. Australia 
10. What are twisters?

a. Strong hurricanes which kill hundreds of people in the United States every year.

b. Tornado-like whirlwinds which occur in Finland, for example.

c. Splinters of stones thrown into air during a volcanic eruption.

d. Earthquake waves.

\section{Floods cause}

a. less damage in Ostrobothnia than in Finnish Lakeland.

b. half of all deaths in the world caused by natural catastrophes.

c. depletion of soil nutrients in the floodplains of rivers.

d. more damage in natural rivers than in rivers that have been turned into straight canals.

12. Hot weather can be a threat to human lives because

a. air-conditioning devices are ineffective.

b. hot weather is difficult to predict and there are no advance warnings.

c. hot weather disrupts railway schedules.

d. the temperature regulation system in a human body is working at its limits when the surrounding temperature rises to $40^{\circ} \mathrm{C}$.

13. Erosion, the wearing away of the soil, is accelerated

a. if terrace plantations are built on steep slopes instead of fields that naturally follow to the shape of the slopes.

b. if treeless areas are forested.

c. due to logging of forests, agriculture and animal husbandry.

d. due to thickening of the plant cover.

14. The most significant harmful effects from an unbalanced diet
a. are more common in the population of working age than in children.
b. are less significant than the harmful effects of excessive eating.
c. are caused by lack of proteins, minerals, vitamins and fibre.
d. are caused by insufficient caloric intake.

15. Which disease spreads through dirty drinking water?
a. typhoid fever
b. malaria
c. AIDS
d. Ebola

16. Which of the following statements related to natural biodiversity is correct?

a. Biological diversity has increased over the last centuries.

b. Climate change decreases the natural biodiversity in arctic areas. 
c. Genetic diversity is not part of biological diversity.

d. Out of all ecosystems, wetlands have suffered the least from decrease of biodiversity.

17. Which one of the following statements related to climate change is incorrect?

a. The average temperature on Earth is estimated to rise 1-5 degrees Celsius in a hundred years.

b. The strengthening of the greenhouse effect is mainly due to carbon dioxide and other greenhouse gas emissions from usage of fossil fuels.

c. Climate change makes it easier to cultivate grain in regions around the equator.

d. The surface level of oceans will rise due to climate change.

18. Climate change can be slowed down

a. by planning the infrastructure of an area so that motor vehicles are used as little as possible.

b. by increasing one's own carbon footprint.

c. by increasing methane emissions.

d. by increasing consumption of fossil fuels in developing countries.

19. Ozone depletion is

a. less often noticeable above the Antarctica than in the North Pole area.

b. a significant environmental problem in the lower levels of the atmosphere.

c. a significant environmental problem in the upper atmosphere, the stratosphere.

d. decreased due to freon and halon emissions.

20. The problem with urbanization is

a. formation of smoke fog, or smog.

b. decrease of floods as rain water is directed to storm water drains.

c. merging of the residential areas of the well off and the disadvantaged people.

d. increasing biodiversity.

\section{Answer the following questions in writing:}

21. Compare the threats of volcanic eruptions and climate change. What differences are there in the nature of these threats?

22. How can slowing down of climate change be useful in Sub-Saharan Africa?

23. There are regular floods in a certain area.

a. What could cause the floods?

b. How could the inhabitants decrease flood damages?

c. Which kind of damage caused by floods is the most harmful, in your opinion? Explain briefly. 